TECHNICAL TRANSACTIONS 9/2018

CHEMISTRY

DOI: $10.4467 / 2353737$ XCT.18.132.8971 SUBMISSION OF THE FINAL VERSION: $2 / 8 / 2018$

\author{
Barbara Larwa (iD) orcid.org/0000-0003-1762-6694 \\ bl@chemia.pk.edu.pl \\ Monika Gwadera \\ Izabela Kicińska \\ Krzysztof Kupiec \\ Chair of Chemical and Process Engineering, Faculty of Chemical Engineering \\ and Technology, Cracow University of Technology
}

\title{
PARAMETERS OF THE CARSLAW-JaEger EQUATION \\ DESCRIBING THE TEMPERATURE DISTRIBUTION IN THE GROUND
}

\author{
PARAmetry RÓWNANIA CARSLAWA-JaEgERA \\ OPISUJĄCEGO ROZKEAD TEMPERATURY W GRUNCIE
}

\begin{abstract}
The ground temperature changes with depth and time. Time variability is considered as a harmonic function. The equation describing changes of the ground temperature contains four parameters: the average annual temperature of the surface of the ground, the annual amplitude of the temperature of the ground surface as well as the phase angle of the temperature and thermal diffusivity of the ground. Based on the results of the measurements presented in the literature, the parameters of the equation using the combined method on the basis of linear regression, described in the literature, were determined. This method, however, leads to an ambiguous value of the thermal diffusivity. It was found that the nonlinear regression method gives much better results, leading to obtaining precise and unambiguous values of all parameters of the equation.
\end{abstract}

Keywords: temperature distribution in the ground, nonlinear regression

\section{Streszczenie}

Temperatura gruntu zmienia się z glębokością oraz w czasie. Zmienność czasowa ma charakter harmoniczny. Równanie opisujące zmiany temperatury gruntu zawiera cztery parametry: średnioroczną temperaturę powierzchnigruntu, roczną amplitudę temperatury powierzchnigruntu, kąt fazowy oraz dyfuzyjnośćcieplną gruntu. Na podstawie wyników pomiarów przedstawionych w literaturze wyznaczono parametry równania kombinowaną metodą opierającą się na regresji liniowej, opisaną w literaturze. Metoda ta prowadzi jednak do otrzymania niejednoznacznej wartości współczynnika dyfuzyjności cieplnej. Stwierdzono, że znacznie lepsze wyniki daje metoda regresji nieliniowej, prowadząc do otrzymania dokładnych i jednoznacznych wartości wszystkich parametrów równania.

Słowa kluczowe: rozkład temperatury w gruncie, regresja nieliniowa 


\section{Introduction}

Knowledge of the temperature distribution in subsurface ground layers is important in the design, modelling and exploitation of ground heat exchangers and other devices related to heat transport in the ground (for example, pipes transporting heat carriers). The ground can be treated as a system composed of a subsurface layer in which there are interactions related to changing weather conditions as well as a deeper layer in which these impacts do not occur.

The ground temperature depends on the latitude, weather conditions, season, altitude, topography, shading, presence of buildings in the neighbourhood, type of surface coverage, ground properties and precipitation. Because many of these parameters change in the seasonal cycle, or irregularly with time, it is not possible to accurately predict the temperature of the ground at any location and at any time, especially in places close to the ground surface. Therefore, the prediction of ground temperature has a statistical nature.

The ground temperature in the subsurface layer depends on the location and time. The thickness of this layer depends on the thermal diffusivity of the ground. For small values of thermal diffusivity, the subsurface layer has a small thickness, whereas when the thermal diffusivity of the ground is high, the ground temperature stabilisation at the level of the undisturbed ground temperature, occurs at greater depths [1]. Due to the thermal inertia of the ground, the amplitude of the ground temperature changes decreases with depth. The amplitude of ground temperature changes caused by daily variability of the ground surface temperature decreases to zero at a depth of about $1 \mathrm{~m}$, while the amplitude caused by seasonal changes decreases with the distance from the ground surface to a much lesser degree.

Carslaw and Jaeger [2] presented a relationship describing the ground temperature as a function of the location (distance from the surface) and time. It is a solution to the equation of heat conduction for the semi-infinite body with a periodic temperature change of its surface.

The results of extensive studies of temporal changes of the ground temperature at various depths in various climatic conditions in the USA were presented by Kusuda and Achenbach [3]. Some of the results of these experiments form the basis for the analysis carried out in the remainder of this paper.

Ground temperature measurements at various depths and in various places around the world are often published in the literature. For example, Badache et al. [4] presented the results of research carried out in Montreal; the ground was analysed to a depth of $26 \mathrm{~m}$. However, the results of research carried out in Poznan City, presented by Popiel and Wojtkowiak [5], concerned research in the depth range up to $17.3 \mathrm{~m}$.

Based on the analysis of the heat fluxes occurring on the ground surface, the surface temperature of the ground can be related to the air temperature, which is characterised by the following parameters: average annual value, annual fluctuation amplitude and phase angle $[6,7]$.

In this paper, the parameters of the Carslaw-Jaeger equation were determined based on the results of ground temperature measurements at various depths. The method used by Kusuda and Achenbach [3] and nonlinear regression were applied. The benefits of nonlinear regression have been presented. Differences between average annual temperature, annual temperature amplitude and phase angle for the ground surface and for the air were also discussed. 


\section{The Carslaw-Jaeger equation}

For theoretical analysis of ground temperature changes with location and time, the following assumptions are made:

- The ground is a homogeneous heat conducting medium,

- The ground can be treated as a semi-infinite medium with constant thermal diffusivity,

- The surface temperature of the ground is variable periodically over time.

The problem of ground temperature has been examined for a long time. The first known works of Lord Kelvin come from 1811. The ground temperature can be described using the Fourier series:

$$
T=T_{s m}+\sum_{n=1}^{\infty} A_{s n} \cdot \exp \left(-\sqrt{n} \frac{x}{L}\right) \cdot \cos \left(n \omega t-P_{s n}-\sqrt{n} \frac{x}{L}\right)
$$

where:

$$
\begin{aligned}
& x-\text { position coordinate }[\mathrm{m}], \\
& t \quad-\text { time }[\mathrm{s}], \\
& T_{s m}-\text { annual average temperature of the ground surface }\left[{ }^{\circ} \mathrm{C}\right], \\
& L-\text { damping depth }[\mathrm{m}] .
\end{aligned}
$$

The $A_{s n}[\mathrm{~K}]$ and $P_{s n}[\mathrm{rad}]$ values correspond respectively to the $n^{\text {th }}$ harmonic component: the annual amplitude of temperature fluctuations on the ground surface and the phase angle. Often, the above relationship is simplified to the form in which only the first expression of the series occurs. This is justified because the higher harmonic elements generally relate to the daily temperature variations of the ground, which is not taken into account here. For $n=1$ the equation has the form:

$$
T=T_{s m}-A_{s} \cdot \exp \left(-\frac{x}{L}\right) \cdot \cos \left(\omega t-P_{s}-\frac{x}{L}\right)
$$

Carslaw and Jaeger [2] in the monograph Conduction of Heat in Solids presented the above dependence as a solution to the equation of heat conduction in a semi-infinite medium whose surface has a periodically variable temperature (this equation was presented by Carslaw in the first edition of the work [8] already in 1906). The solution is of practical importance in determining the temperature of the ground subjected to cyclical actions related to seasonal changes. The solution concerns the case when the geothermal gradient is zero. The damping depth $L$ is defined as follows:

$$
L=\sqrt{\frac{2 a}{\omega}}
$$

where:

$a$ - thermal diffusivity of the ground $\left[\mathrm{m}^{2} / \mathrm{s}\right]$,

$\omega$ - frequency of temperature changes $\left[\right.$ days $\left.^{-1}\right]$ or $\left[\mathrm{s}^{-1}\right]$. 
Phase angle $P_{s}$ is related to the time $t_{\min }$ elapsing from the beginning of the calendar year to the day on which the average daily temperature of the ground surface reaches the minimum value:

$$
P_{s}=\omega t_{\min }
$$

For the phenomena occurring in the annual cycle, the frequency is $\omega=2 \pi / 365$ days $^{-1}$. Due to the neglect of the geothermal flux, the value of the average annual ground temperature $T_{m}$ practically does not depend on the location. Consequently, the undisturbed ground temperature and the annual average surface temperature of the ground are equal.

By introducing substitutions:

$$
\begin{gathered}
T_{m}=T_{s m} \\
A_{x}=A_{s} \cdot \exp \left(-\frac{x}{L}\right) \\
B_{x}=P_{s}+\frac{x}{L}
\end{gathered}
$$

the following dependency is obtained:

$$
T=T_{m}-A_{x} \cdot \cos \left(\omega t-B_{x}\right)
$$

from which it is possible to specify the values of $T_{m}, A_{x}$ and $B_{x}$ for individual depths $x$.

It should be noticed that in some situations the equation (2) must be modified to reflect the real temperature distribution in the ground [9]. This concerns i.a. the case where, due to the presence of groundwater, there is, besides conduction, additional convective heat transfer in the ground. Furthermore, in a cold climate due to the freezing of the ground and snow cover, the relationship (2) does not properly describe the temperature distribution in the ground.

\section{Determining the parameters of the Carslaw-Jaeger equation}

The parameters of Carslaw and Jaeger equation are: average annual temperature of the ground surface $T_{s m}$, annual amplitude of temperature fluctuations of the ground surface $A_{s}$, phase angle $P_{s}$ and damping depth $L$.

Kusuda and Achenbach [3] used the model (2) to determine the parameters $T_{s m}, A_{s}, P_{s}$ and $L$. The method of calculating these parameters based on the results of the measurements presented in Fig. 1 is presented below. The measurements concerned monthly average ground temperatures, averaged over many years, carried out in Argonne (Illinois, USA). Measurements were taken at depths from 0 to $8.84 \mathrm{~m}$, and the results covered all months of the year. Fig. 1 shows exemplary results for four selected months. 


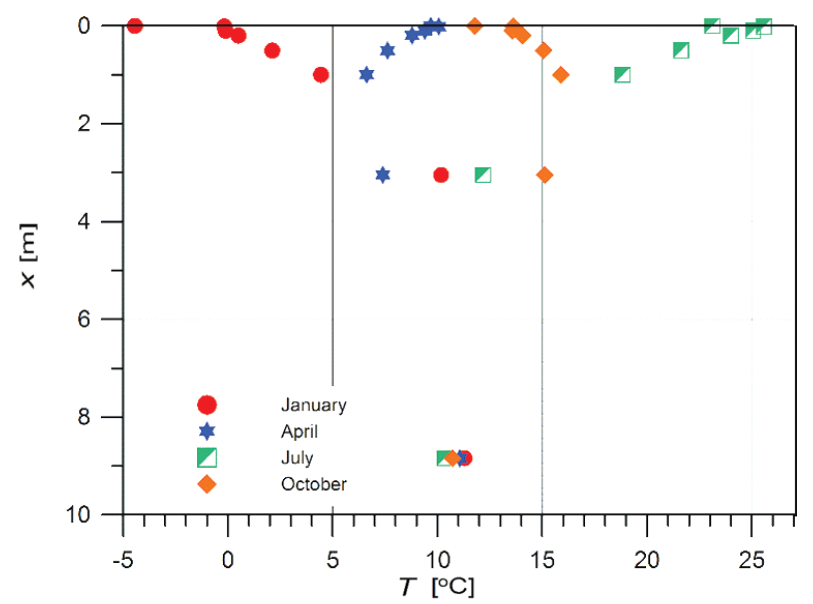

Fig. 1. Sample results of measurements of monthly average ground temperatures at various depths [3]

For the calculations, $96(=12 \cdot 8)$ values of soil temperature measurement data were used. The indirect results of the calculations are presented in Table 1 . The following values are given: the position coordinate $x$ and the coefficients $b_{0}, b_{1}$ and $b_{2}$ of the equation (A.2) (presented in Appendix A) in a linearised form of dependence (8). The relationship between $T_{m}$ and $x$, as shown in Fig. 2, suggests averaging the values $T_{m}$, which gives the value $T_{s m}=11.1^{\circ} \mathrm{C}$.

Table 1. The results of the calculated parameters of equations (A.2) and (8)

\begin{tabular}{|c|c|c|c|c|c|}
\hline $\boldsymbol{x}[\mathbf{m}]$ & $\boldsymbol{b}_{\mathbf{0}}=\boldsymbol{T}_{\boldsymbol{m}}\left[{ }^{\circ} \mathbf{C}\right]$ & $\boldsymbol{b}_{\mathbf{1}}$ & $\boldsymbol{b}_{\mathbf{2}}$ & $\boldsymbol{B}_{\boldsymbol{x}}[\mathbf{r a d}]$ & $\boldsymbol{A}_{\boldsymbol{x}}[\mathbf{K}]$ \\
\hline 0 & 9.47 & -11.29 & -7.853 & 0.608 & 13.75 \\
\hline 0.01 & 11.78 & -10.45 & -8.027 & 0.655 & 13.18 \\
\hline 0.10 & 11.46 & -10.17 & -8.125 & 0.674 & 13.02 \\
\hline 0.20 & 11.36 & -9.18 & -8.209 & 0.730 & 12.31 \\
\hline 0.50 & 11.29 & -6.90 & -8.082 & 0.864 & 10.62 \\
\hline 1.00 & 11.33 & -4.06 & -7.516 & 1.075 & 8.54 \\
\hline 3.05 & 11.26 & 1.10 & -3.770 & $-1.288+\pi$ & 3.93 \\
\hline 8.84 & 10.89 & 0.29 & 0.397 & $0.942+\pi$ & 0.49 \\
\hline Average value & $T_{s m}=11.10$ & \multicolumn{2}{l}{} \\
\hline
\end{tabular}

The consecutive values in the table are $B_{x}$ and $A_{x^{\prime}}$ determined according to the dependencies (A.8) and (A.9) presented in the Appendix. In Fig. 2, the relation between $A_{x}$ and $x$ is shown in a semi-logarithmic system. Since the relationship is approximately linear, the approximation with equation (6) can be used. In this way, the following parameters were determined: $A_{s}=13.1 \mathrm{~K}$ and $L=2.67 \mathrm{~m}$. The same figure also shows the dependence of $B_{x}$ on $x$. The points are arranged on a straight line, which is consistent with the formula (7). The determined constants are: $P_{s}=0.651 \mathrm{rad}$ and $L=2.57 \mathrm{~m}$. Thus, the values of parameters $L, A_{s}$ and $P_{s}$ were determined, with the damping depth determined by two methods: amplitude and phase angle, yielding different results. 


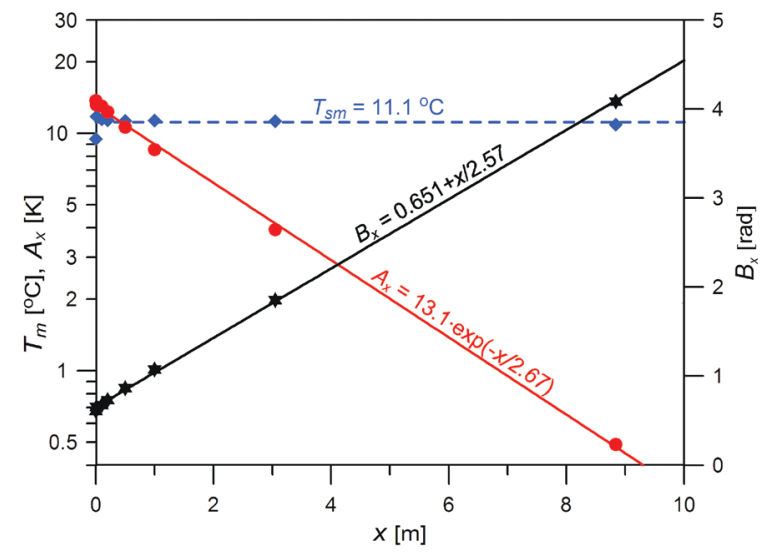

Fig. 2. Dependence of $T_{m}, A_{x}$ and $B_{x}$ on the position coordinate $x$

Another way to determine the parameters of equation (2) is the use of nonlinear regression. An iterative method was applied consisting in the repeated use of the least squares technique for different values of damping depth $L$. The calculation method for the known $L$ value is shown in Appendix B. The estimated value of parameter $L$ corresponds to the minimum sum of squared errors of experimental and calculated $S S$ values.

The parameters of equation (2) can also be determined by nonlinear regression directly e.g. by using the Solver application from the Excel package. The minimum value of SS is sought, with the algorithm based on solving the algebraic system of nonlinear equations. As initial values the following parameters $L=2 \mathrm{~m}, T_{m}=10^{\circ} \mathrm{C}, A_{s}=12 \mathrm{~K}$ and $P_{s}=0.5 \mathrm{rad}$ were assumed. Then the ground temperature was calculated using Eq. (2). Parameters presented in Table 2 (Excel) were obtained for the minimum sum of squared errors is $S S=73.48$.

Table 2. alculation results of the equation (2)

\begin{tabular}{|c|c|c|c|c|c|}
\cline { 2 - 6 } \multicolumn{1}{c|}{} & $\begin{array}{c}\text { Amplitude } \\
\text { method [3] }\end{array}$ & $\begin{array}{c}\text { Phase lag } \\
\text { method [3] }\end{array}$ & $\begin{array}{c}\text { Nonlinear } \\
\text { regression } \\
\text { (App. B) }\end{array}$ & $\begin{array}{c}\text { Nonlinear } \\
\text { regression } \\
\text { (Excel) }\end{array}$ & $\begin{array}{c}\text { Designated } \\
\text { in [3] }\end{array}$ \\
\hline Average temperature $T_{m}\left[{ }^{\circ} \mathrm{C}\right]$ & 11.1 & 11.1 & 11.1 & 11.1 & 10.6 \\
\hline Amplitude $A_{s}[\mathrm{~K}]$ & 13.1 & 13.1 & 13.4 & 13.4 & 12.8 \\
\hline Phase angle $P_{s}[\mathrm{rad}]$ & 0.651 & 0.651 & 0.639 & 0.634 & 0.7 \\
\hline Damping depth $L[\mathrm{~m}]$ & 2.67 & 2.57 & 2.38 & 2.38 & 2.60 \\
\hline
\end{tabular}

Table 2 presents the values of the parameters of equation (2) obtained:

- Application of the equation (8) with the determination of the value $L$ on the basis of the dependence of the amplitude $A_{x}$ on the $x$ (amplitude method),

- Application of the equation (8) with the determination of the value $L$ based on the dependence of the phase angle on the $x$ (phase angle method),

- By using nonlinear regression with the iterative determination of $L$ value,

- By using the Solver application from the Excel package,

- Designated in the paper [3]. 


\section{The accuracy analysis of the obtained parameters}

On the basis of the designated parameter values: $T_{s m}, A_{s}, P_{s}$ and $L$, according to the dependence (2), the soil temperature at different depths and at different periods of the year was determined. The results of the calculations together with the results of the measurements are shown in Fig. 3a, b, c and d. Compatibility with the results of the experiments is good; the best is for parameter values determined from nonlinear regression. Parameter values obtained by nonlinear regression methods: iterative and using the Excel package were identical.

Fig. 4 presents a comparison of experimental and calculation results for the entire time interval and for two coordinate positions: $x=0.2 \mathrm{~m}$ and $x=3.05 \mathrm{~m}$.

a)

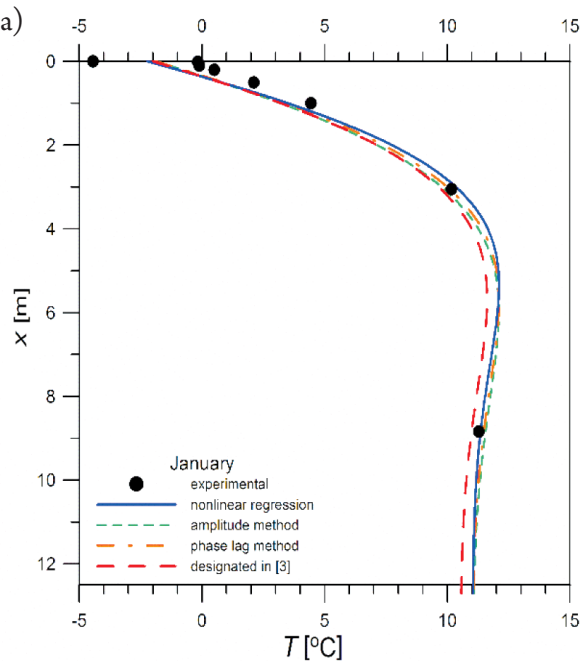

c)

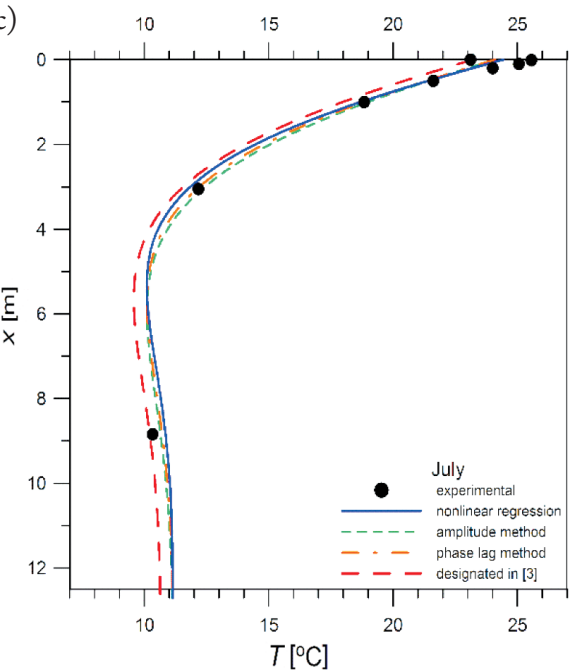

b)

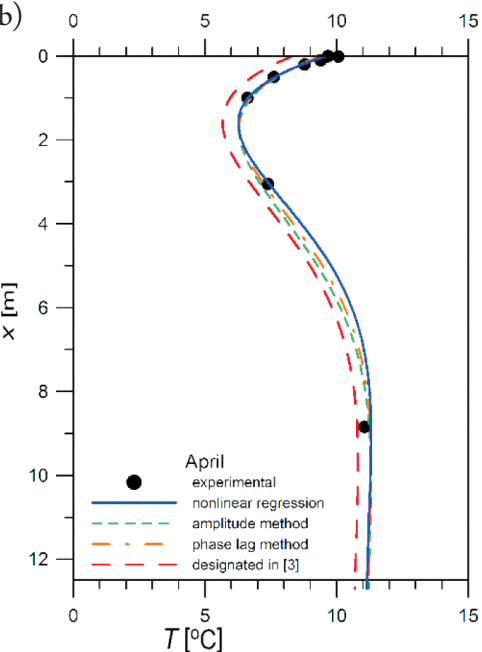

d)

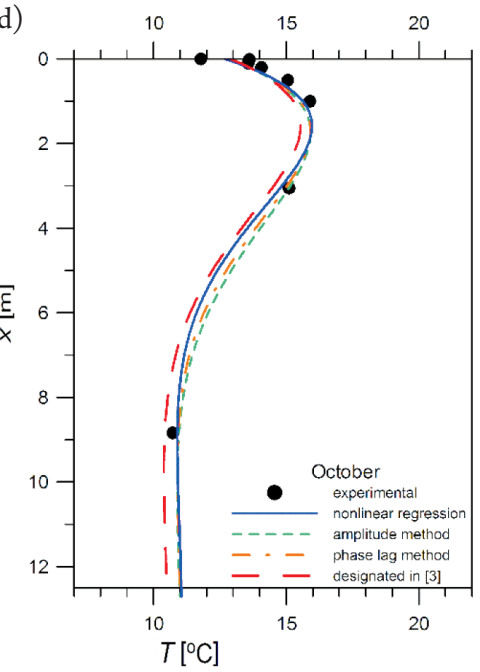

Fig. 3. Comparison of measurement results with the results of calculations in various methods: a) January, b) April, c) July, d) October 
Fig. 3a, b, c, d and Fig. 4 show that the best compliance with the results of the experiment is obtained by nonlinear regression, and the largest deviations refer to computational values determined on the basis of the values given in work [3].

Direct comparison of experimental and computational results obtained by using nonlinear regression and obtained on the basis of values presented in work [3] is shown in Fig. 4. Most absolute errors are smaller than $1.5 \mathrm{~K}$ and the biggest errors concern small and large temperature values (occurring at the ground surface). In the middle temperature range, corresponding to the large depths, the errors are low. Moreover, the graph confirms good compatibility between the nonlinear regression calculation results and measurement values.

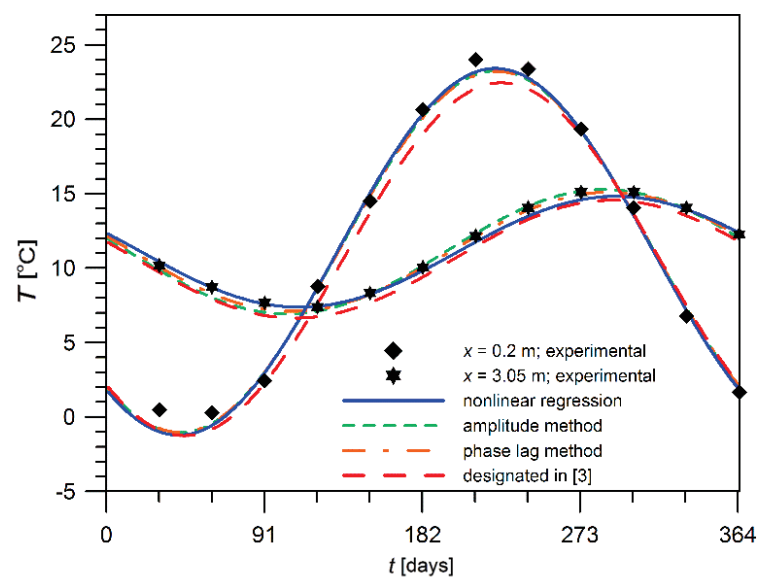

Fig. 4. Comparison of experimental and calculation results for $x=0.2 \mathrm{~m}$ and $x=3.05 \mathrm{~m}$

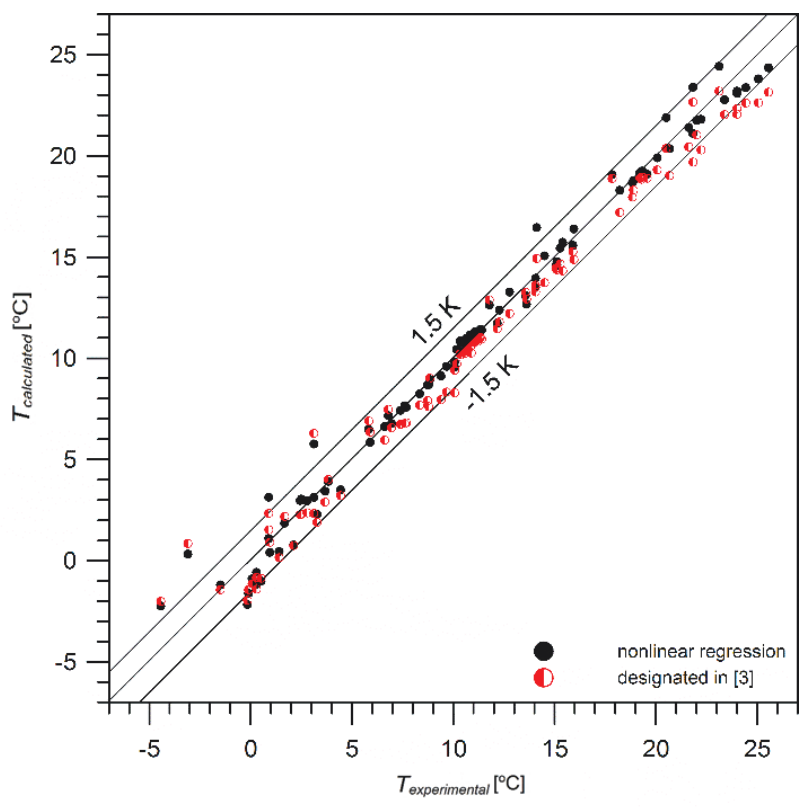

Fig. 5. Compatibility of experimental and calculation results 
The average deviation between experimental and computational temperatures (based on the values of parameters determined by non-linear regression) is equal to:

$$
\sigma=\sqrt{\frac{S S}{n-m}}=\sqrt{\frac{73.48}{96-4}}=0.89 \mathrm{~K}
$$

where:

$$
\begin{aligned}
& n \text { - the number of measurements, } \\
& m \text { - the number of determined parameters. }
\end{aligned}
$$

\section{Comparison of the values of the equation parameters determining the ground surface and the ambient temperature}

It is interesting to compare the values of the parameters of equation (2): $T_{s m}, A_{s}$ and $P_{s}$ with the values of the parameters of the equation describing the temporal variability of the ambient temperature:

$$
T_{a}=T_{a m}-A_{a} \cdot \cos \left(\omega t-P_{a}\right)
$$

In the above equation: $T_{a m}$ - average annual ambient temperature $\left[{ }^{\circ} \mathrm{C}\right], A_{a}-$ annual amplitude of ambient temperature fluctuations $[\mathrm{K}], P_{a}$ - phase angle for ambient temperature corresponding to the time which elapses from the beginning of the calendar year to the day in which the average ambient temperature reaches the minimum value [rad]. In work [3], the appropriate values were compared, and it was found that:

- For many sites, near equality of the average annual ambient temperatures $T_{a m}$ and the average annual temperature of the ground $T_{s m}$ can be approximated. This regularity does not apply to mountain climates.

- For inland sites, the amplitude of the ground surface $A_{s}$ is less than the amplitude of the ambient temperature $A_{a}$. The reverse relation concerns areas near the coast.

- The phase angles of the annual ambient temperature cycles are concentrated in a narrow range (deviations \pm 0.05 radians), while the phase angles of the temperature of the ground surface are dispersed in a wider range (deviations \pm 0.2 radians).

\section{Conclusions and final remarks}

In this paper, the parameters of the Carslaw-Jaeger equation were determined based on the results of ground temperature measurements at various depths. A combined method based on the linear regression and the nonlinear regression method was used. It was found that the first method leads to ambiguous values of the thermal diffusivity. The nonlinear regression method gives much better results, leading to precise and unambiguous values of all parameters of the equation. 
Compatibility of computational values with the results of experiments is good; the best for values of parameters determined from nonlinear regression. Most of the absolute errors are less than $1.5 \mathrm{~K}$. The biggest errors concern temperatures measured near the ground surface.

As the data for the calculations, the measurement values presented in work [3] were used, which refer to monthly average temperature values. Temperature values had to be assigned to the time values. When assigning temperature values for the $k^{\text {th }}$ month to the time values $(k-0.5) \cdot 365 / 12$ (day of the year corresponding to the middle of this month), the obtained phase angle values $P_{s}$ were less by about $0.26 \mathrm{rad}$ than the value given by the authors. Since this difference corresponds to $t \approx 15$ days, further calculations were carried out by assigning temperature in the $k$-th month time $k \cdot 365 / 12$, which corresponds to the end of the month (Fig. 4). Therefore, the $P_{s}$ value should be considered as contractual, depending on the assumed origin of the time-coordinate system.

\section{Appendix A. Linear regression}

Using the trigonometric identity:

$$
\cos (\alpha \pm \beta)=\cos \alpha \cdot \cos \beta \mp \sin \alpha \cdot \sin \beta
$$

dependence (8) can be transformed into the form:

$$
Y=b_{0}+b_{1} X_{1}+b_{2} X_{2}
$$

where the dependent variable $Y=T$ and the independent variables are defined as follows:

$$
\begin{aligned}
& X_{1}=\cos (\omega t) \\
& X_{2}=\sin (\omega t)
\end{aligned}
$$

The coefficients from the equation (A.2) are associated with the coefficients from the equation (8):

$$
\begin{gathered}
b_{0}=T_{m} \\
b_{1}=-A_{x} \cdot \cos B_{x} \\
b_{2}=-A_{x} \cdot \sin B_{x}
\end{gathered}
$$

After determining the coefficients $b_{0}, b_{1}$ and $b_{2}$ using the least squares method, $B_{x}$ and $A_{x}$ can be calculated according to the formulas resulting from (A.6) and (A.7):

$$
B_{x}=\arctan \left(\frac{b_{2}}{b_{1}}\right)
$$




$$
A_{x}=-\frac{b_{2}}{\sin B_{x}}
$$

\section{Appendix B. Nonlinear regression}

It is not possible to transform the equation (2) to the linear form due to the determined parameters $T_{s m^{\prime}} A_{s} P_{s}$ and $L$. However, the problem can be solved by using an iterative method relative to the parameter $L$. The used algorithm consisted in a trial assumption of $L$ and calculation of the sum of squared errors SS. By reiterating that calculation, the $L$ value, for which the $S S$ value reaches the minimum, can be determined.

For the trial value $L$, the equation (2) can be reduced to the form:

$$
Y=b_{0}+b_{1} X_{1}+b_{2} X_{2}
$$

where the dependent variable $Y=T$ and the independent variables are defined as follows:

$$
\begin{aligned}
& X_{1}=\exp \left(-\frac{x}{L}\right) \cdot\left[\cos \left(\frac{x}{L}\right) \cdot \cos (\omega t)+\sin \left(\frac{x}{L}\right) \cdot \sin (\omega t)\right] \\
& X_{2}=\exp \left(-\frac{x}{L}\right) \cdot\left[\cos \left(\frac{x}{L}\right) \cdot \sin (\omega t)-\sin \left(\frac{x}{L}\right) \cdot \cos (\omega t)\right]
\end{aligned}
$$

wherein the trigonometric identity (A.1) was used.

The coefficients from equation (B.1) are associated with the coefficients from equation (2):

$$
\begin{gathered}
b_{0}=T_{m} \\
b_{1}=-A_{s} \cos \left(P_{s}\right) \\
b_{2}=-A_{s} \sin \left(P_{s}\right)
\end{gathered}
$$

After determining the coefficients $b_{0}, b_{1}$ and $b_{2}$ using the least squares method, $P_{s}$ and $A_{s}$ can be calculated according to the formulas resulting from (B.5) and (B.6):

$$
\begin{gathered}
P_{s}=\arctan \left(\frac{b_{2}}{b_{1}}\right) \\
A_{s}=-\frac{b_{2}}{\sin \left(P_{s}\right)}
\end{gathered}
$$

The last step of the algorithm is to calculate, according to (2), the value of temperature $T_{\text {calculated }}$ based on the sample values of parameters $T_{m}, A_{s} P_{s}$ and $L$, and then the calculation of the sum of squared errors of calculation and experimental values according to the formula:

$$
S S=\sum_{i=1}^{n}\left(T_{\text {calculated }}-T_{\text {experimental }}\right)^{2}
$$




\section{References}

[1] Kurevija T., Vulin D., Krapec V., Influence of undisturbed ground temperature and geothermal gradient on the sizing of borehole heat exchangers, Proceedings of the World Renewable Energy Congress, Linkoping, Sweden, 8-13 May 2011, 1360-1367.

[2] Carslaw H.S., Jaeger J.C., Conduction of Heat in Solids, second ed., Clarendon Press, Oxford 1959.

[3] Kusuda T., Achenbach P.R., Earth temperature and thermal diffusivity at selected stations in the United States, National Bureau of Standards Report Nr 8972, June 1965.

[4] Badache M., Eslami-Nejad P., Ouzzane M., Aidoun Z., A new modeling approach for improved ground temperature profile determination, Renewable Energy 2016, 85, 436-444.

[5] Popiel C.O., Wojtkowiak J., Temperature distributions of ground in the urban region of Poznan City, Experimental Thermal and Fluid Science 2013, 51, 135-148.

[6] Krarti M., Lopez-Alonzo C., Claridge D.E., Kreider J.F., Analytical model to predict annual soil surface temperature variation, Journal of Solar Energy Engineering, 1995, 117, 91-99.

[7] Gwadera M., Larwa B., Kupiec K., Undisturbed ground temperature - different methods of determination, Sustainability 2017, 9, 2055.

[8] Carslaw H.S., Introduction to the mathematical theory of the conduction of heat in solids, MacMillan and Co., Limited, London 1921.

[9] Rees S.J. (Ed.), Advances in Ground-Source Heat Pump Systems, Elsevier 2016. 